\title{
Boletim Ferramenta: a comunicação popular como instrumento da Pastoral Operária da Arquidiocese de Vitória na mobilização dos trabalhadores nas décadas de 70 e 80
}

\author{
José Edgard REBOUÇAS ${ }^{1}$ \\ Elaine Rodrigues Dal GOBBO ${ }^{2}$
}

\begin{abstract}
Resumo:
O artigo aborda a participação do boletim Ferramenta, da Pastoral Operária da Arquidiocese de Vitória, no Espírito Santo, na mobilização dos trabalhadores nas décadas de 70 e 80 . O estudo faz uma breve retrospectiva do surgimento da Teologia da Libertação para possibilitar a compreensão de como se originaram as pastorais sociais e do estopim da comunicação popular para, posteriormente, abordar como foram os primeiros passos da Igreja progressista e da Pastoral Operária no Espírito Santo. Em seguida, os autores abordam o surgimento do boletim Ferramenta, seus objetivos, o processo de produção e destacam sua participação na mobilização dos trabalhadores da construção civil, que deflagraram a primeira greve ocorrida no Espírito Santo durante o regime militar. Para elaborar o artigo foram feitos estudos bibliográficos, entrevistas e análises de alguns exemplares do Ferramenta.

Palavras chave:

Comunicação popular; Pastoral Operária; Boletim Ferramenta.

\section{Boletim Ferramenta: popular communication as an instrument of the Archidiocese of Vitória's Workers Pastoral in mobilizing workers in the 1970s and 1980s}

\begin{abstract}
:
The article discusses the participation of the boletim Ferramenta, from Archidiocese of Vitória's Workers Pastoral, in Espírito Santo, in the mobilization of the working class in the 1970s and 1980s. The study briefly reviews the emergence of Liberation Theology in order to understand the rise of pastoralism and its role as the catalyst for popular communication, to then address the first steps of the Progressive Church and the Worker's Pastoral in Espírito Santo. Next, the authors debate the birth of boletim Ferramenta, its objectives, the production process and highlight its participation in the mobilization of construction workers, which initiated the first strike occurred in Espírito Santo during the military regime. In order to elaborate the article, bibliographical studies, interviews and analyzes of some copies of Ferramenta were made.
\end{abstract}

Keywords:

Popular communication; Workers Pastoral; Boletim Ferramenta.

\footnotetext{
${ }^{1}$ José Edgard Reboucas tem formação em Comunicação Social/Jornalismo pela Universidade Federal do Espírito Santo (1990), mestrado em Sciences de lInformation et de la Communication - Université Grenoble 3 (1994) e doutorado em Comunicação Social pela Universidade Metodista de São Paulo, com estágio de pesquisa na Université du Québec à Montréal (2003). É professor Associado da Universidade Federal do Espírito Santo (UFES), superintendente de Cultura e Comunicação da UFES, coordenador do Observatório da Mídia: direitos humanos, políticas, sistemas e transparência. Tem experiência na área de pesquisa em Comunicação, com ênfase em Indústrias Culturais e Políticas de Comunicações, atuando principalmente nos seguintes temas: regulação/regulamentação, direitos humanos, televisão, jornalismo, publicidade, educomunicação e observatórios de mídia. E-mail: edreboucas.br@gmail.com

${ }^{2}$ Elaine Rodrigues Dal Gobbo é jornalista formada pela Universidade Federal do Espírito Santo (2008), onde também cursou a especialização em Gestão Estratégica de Marketing (2012). Atualmente é mestranda do Programa de Pós Graduação em Comunicação \& Territorialidades dessa mesma instituição de ensino. É orientanda do professor doutor José Edgard Rebouças. E-mail: elaine.jornalista@yahoo.com.br
} 
Boletim Ferramenta: la comunicación popular como instrumento de la Pastoral Obrera de la Arquidiocesis de Vitória en la movilización de los trabajadores en las décadas de los 70 y 80

\begin{abstract}
Resumen:
El artículo aborda la participación del boletín Ferramenta, de la Pastoral Obrera de Arquidiócesis de Vitória, en el estado brasileño de Espírito Santo, en la movilización de trabajadores en las décadas de 1970 y 1980. El estudio hace una retrospectiva breve del surgimiento de la Teología de la Liberación para permitir el entendimiento de cómo se han originado las pastorales sociales y el despertar de la comunicación popular, para después enseñar cómo han sido los primeros pasos de la Iglesia progresista y de la Pastoral Obrera en Espírito Santo. En seguida, los autores tratan de la creación del boletín Ferramenta, sus objetivos, el proceso de producción, y destacan su participación en la movilización de los trabajadores de construcción que hicieron la primera huelga en Espírito Santo durante el régimen militar. Para preparar el artículo han sido hechos estudios bibliográficos, entrevistas y análisis de algunas ediciones de Ferramenta.
\end{abstract}

Palabras clave:

Comunicación popular; Pastoral Obrera; Boletín Ferramenta.

\title{
INTRODUÇÃO
}

No fim dos anos 40 aplicou-se na América Latina, sem ajustes, o mesmo modelo de desenvolvimento que vigorava nos Estados Unidos e Europa Ocidental. Contudo, esse modelo começou a demonstrar sua inoperância e passou a ser questionado por meio de uma proposta chamada Teoria da Dependência. Essa teoria denunciava, por exemplo, a injustiça existente nas relações comerciais entre a América Latina e os Estados Unidos, como o déficit causado aos latino-americanos em virtude da venda de matérias primas baratas para os Estados Unidos e a compra de produtos caros vindos desse país. Logo, somente mudando essa estrutura de dependência seria possível um desenvolvimento verdadeiramente democrático (SALMÓN, 2005).

A Teoria da Dependência influenciou na criação da Teologia da Libertação, que propõe uma teologia com reflexão crítica da práxis histórica, que não somente pensa o mundo, mas também procura se situar num processo de transformação do mundo, abrindo-se para a luta pela dignidade humana e construção de uma sociedade justa e fraterna (GUTIÉRREZ, 2000).

Na década de 60 o Papa João XXIII convocou o Concílio Vaticano II, que abriu as perspectivas para que a Igreja Católica se colocasse ao lado dos pobres. Após esse Concílio houve uma conferência episcopal latino-americana em Medellín, na Colômbia, na qual a Igreja defendeu que a pobreza é um mal e que deve haver solidariedade em relação aos pobres e protestos contra a realidade que eles vivem. Nesse contexto, difunde-se, dentro da Igreja, aquele que é o tema central da Teologia da Libertação: a opção preferencial pelo pobre. Tem início também a prática de Comunidades Eclesiais 
de Base (Ceb's), que se trata da presença da Igreja em pequenas comunidades, levando reflexão social e política principalmente para as periferias. Esses ideais foram ratificados na Conferência de Puebla, no México, em 1979 (GUTIÉRREZ, 2000).

Nesse contexto nascem também as pastorais sociais, que se trata da caridade e solicitude para com aqueles cuja vida está ameaçada. Elas concretizam a opção preferencial pelos pobres, por quem vive de forma desumana. Sua missão passa pela organização dos excluídos, pelas mobilizações sociais e comprometimento político. O contexto de surgimento das pastorais sociais remonta à Ditadura Militar, principalmente ao governo do general Emílio Garrastazu Médici, que foi de 1969 a 1974 (CONFERÊNCIA NACIONAL DOS BISPOS DO BRASIL, 2008). Nesse governo, o Brasil viveu o chamado "Milagre Econômico". Havia um crescimento econômico pautado no papel do Estado como impulsionador do grande capital nacional e internacional, no investimento em grandes empreendimentos, por exemplo (GIANNOTTI, 2007).

Um dos locais onde os grandes empreendimentos chegaram foi na Amazônia. Considerado um “território sem gente" pelos militares, esse espaço passou a ser polo de atração para empresários nacionais e internacionais. Com seu direito à terra totalmente violado diante dessa situação, os camponeses se uniram aos membros da Igreja para dar visibilidade às diversas formas de violência pelas quais estavam passando. Foi quando surgiu, em 1975, a Comissão Pastoral da Terra (CPT), que nasceu do "Encontro de Pastoral da Amazônia". A partir daí surgiram outras pastorais, como Pastoral do Menor, Pastoral dos Migrantes, Pastoral da Mulher Marginalizada, Pastoral Carcerária e Pastoral Operária (CONFERÊNCIA NACIONAL DOS BISPOS DO BRASIL, 2008).

Nesse cenário de questionamentos acerca das desigualdades existentes no terceiro mundo, a comunicação não ficou de fora. Na América Latina os debates sobre a democratização da comunicação ganharam espaço, trazendo reflexões sobre o vínculo entre comunicação e organização popular. A comunicação popular ganhou importância dentro da Igreja Católica por meio de mídias como jornais impressos, projetos audiovisuais, entre outros (PUNTEL, 1994).

E o que é a comunicação popular? Ela é formada por iniciativas de movimentos sociais, segmentos populacionais organizados e associações sem fins lucrativos, por exemplo. Entre seus objetivos estão promover mobilização social e conscientização. Essa comunicação vai muito além dos jornais e sua origem se vincula à ação dos 
movimentos populares dos anos 70, durante o período ditatorial (PERUZZO, 2008).

Muitas pastorais sociais investiram na comunicação como instrumento de mobilização, como a Pastoral Operária da Arquidiocese de Vitória, por meio do informativo Ferramenta, objeto de estudo deste artigo, que abrange as décadas de 70 e 80, como forma de estudar como se deu a participação desse veículo de comunicação na mobilização dos trabalhadores, principalmente no período ditatorial, quando a organização popular era fortemente reprimida.

\section{Igreja progressista no Espírito Santo}

Antes de resgatar a história do Ferramenta e abordar sua participação na mobilização dos trabalhadores é importante resgatar como se deu a introdução dos ideais da Teologia da Libertação no Espírito Santo e o surgimento da Pastoral Operária nesse Estado.

Um dos principais responsáveis pela aplicação dos ideais da Teologia da Libertação em solo capixaba foi o bispo Dom João Batista da Mota e Albuquerque, que teve como um de seus apoiadores o bispo auxiliar Dom Luís Gonzaga Fernandes. Dom João tomou posse em 1957 como bispo do Espírito Santo. Ele participou do Concílio Vaticano II e se empenhou em aplicar as novidades estabelecidas. Uma delas foi a realização de missas em português, prática que ele já havia introduzido parcialmente antes mesmo do Concílio com as chamadas missas dialogadas, ou seja, com alguns trechos na língua nacional para incentivar a participação dos fiéis (GURGEL, 2005).

Dom João não se empenhou somente em mudanças litúrgicas. Com apoio do padre Alberto Fontana e do Frei Betto ${ }^{3}$, o bispo criou, em 1976, uma equipe de assessoria social, econômica e política cujo objetivo era prestar serviço às comunidades, aos pequenos grupos de Igreja e de excluídos, como mulheres e trabalhadores. Além disso, foi criado o Centro de Documentação da Arquidiocese de Vitória (Cedives). Para estar à frente desses projetos foram contratados 12 jovens atuantes na Pastoral da Juventude. Por meio dessa iniciativa eram ministrados cursos de educação libertadora, direito à terra, saúde comunitária e, também, foram criadas pastorais, como a Comissão Pastoral da Terra e a Pastoral Operária (GURGEL, 2005).

O Cedives também teve como um de seus papeis fomentar a comunicação da Arquidiocese, como relata o aposentado, militante das Comunidades Eclesiais de Base e

\footnotetext{
${ }^{3}$ Frei Beto havia acabado de sair da prisão, em 1973, e foi morar em Vitória, no bairro Ilha de Santa Maria.
} 
ex-deputado estadual do Espírito Santo pelo Partido dos Trabalhadores (PT), Claudio Humberto Vereza Lodi.

Fui contratado por Dom João, juntamente com minha esposa, Tereza Côgo, que na época era minha noiva, para trabalhar no Cedives. Na época quase todas as dioceses tinham um centro de documentação que produzia e fazia releitura de materiais de escritos populares, além de fazer troca desses materiais entre si. O centro de documentação não era somente para arquivar materiais, era também para produzir. Por exemplo, saía um documento dos bispos do Brasil. A linguagem era de bispo. Então a gente fazia uma versão popular. (LODI, 2016, informação verbal).

A Pastoral Operária surge não somente num cenário de apogeu dos ideais progressistas dentro da Igreja, mas também num momento de reestruturação econômica do Espírito Santo. A economia capixaba deixa de ser pautada principalmente no setor agrário e parte para a industrialização. Até a década de 60 predominava a cafeicultura. De 60 até o início dos anos 70 têm início o crescimento da pecuária bovina e o processo industrial. Em meados dos anos 70 começa a implantação dos "Grandes Projetos Industriais", dos quais destacam-se as empresas de Pelotização da Companhia Vale do Rio Doce, Samarco Mineração, Aracruz Florestal, Companhia Siderúrgica de Tubarão (CST) e modernização da Companhia Ferro e Aço de Vitória (Cofavi). Desses empreendimentos, somente a Samarco e a Aracruz Celulose não se localizavam na Grande Vitória. Portanto, grande parte dos empregos gerados estavam nessa região (SIQUEIRA, 2010).

Uma das consequências desse novo cenário econômico foi a chegada de migrantes para a Grande Vitória, aumentando o número de trabalhadores que se fixavam nesse local em busca de trabalho. Eram pessoas provenientes do interior do Espírito Santo e de outros estados, formando um grande contingente de mão de obra pouco qualificada. Muitas delas sofreram um processo de marginalização. As desigualdades regionais e sociais foram acentuadas. Vitória e os municípios próximos, Cariacica, Serra, Vila Velha e Viana, passaram a enfrentar a ocupação desordenada e a necessidade de atender aos novos moradores com emprego, moradia, infraestrutura, serviços urbanos, entre outros (SIQUEIRA, 2010).

Diante dessa realidade, de acordo com o metalúrgico aposentado e militante da Pastoral Operária da Arquidiocese de Vitória, José Ferreira Machado, surgiu a necessidade de mobilizar os trabalhadores. 
Meu amigo, Maurício Amorim ${ }^{4}$, conheceu a experiência da Ação Católica Operária, existente em São Paulo, através de umas freiras de lá que vieram atuar aqui e quis implantá-la no Espírito Santo. Para isso, convidou diversos amigos das Comunidades Eclesiais de Base, entre eles eu, que na época era metalúrgico e trabalhava na empresa Metalpen, em Campo Grande ${ }^{5}$. Com o passar do tempo, começaram as reflexões sobre a necessidade de abandonar o nome Ação Católica Operária, já que o operariado não era formado somente por católicos. Foi quando o grupo de São Paulo veio para cá e nós ficamos dois dias numa assembleia. Daí surgiu um novo nome. De Ação Católica Operária o grupo passou a se chamar Pastoral Operária. (MACHADO, 2016, informação verbal).

Os grupos de Pastoral Operária eram mais fortes nos municípios de Cariacica e Serra, segundo José Ferreira Machado.

Esses municípios tinham o maior número de operários da construção civil, metalúrgicos e ferroviários, principais públicos com os quais a Pastoral trabalhava, e que foram atraídos pelos grandes empreendimentos industriais. A categoria comerciária era foco da Juventude Operária Católica por ser composta principalmente de jovens. (MACHADO, 2016, informação verbal).

\section{Boletim Ferramenta: o surgimento}

De acordo com Claudio Humberto Vereza Lodi, foi a equipe do Cedives que deu o pontapé inicial para a criação do Ferramenta, a pedido do padre francês Jean

Fugeray ${ }^{6}$, que coordenava a Pastoral Operária na época, Maurício Amorim e Waldemar Almeida Lyrio ${ }^{7}$.

Os jornais da grande mídia não faziam matérias que servissem para formação e informação. Por isso eles pediram a nós que elaborassem um jornal para a Pastoral. Os movimentos de trabalhadores não tinham repercussão em $A$ Gazeta, A Tribuna e $O$ Diário $^{8}$. Os trabalhadores já estavam agindo a partir da Pastoral Operária. Faziam pequenos movimentos, estavam organizando chapas de oposição aos sindicatos. Foi o trabalho pastoral que gerou lideranças que quiseram tomar o sindicato das mãos dos pelegos, nomeados pela ditadura. Os jornais da grande mídia eram censurados ou faziam auto censura, pois qualquer movimento popular ou sindical era considerado subversivo. A grande mídia sempre representativa do grande capital, ou do capital que lhe financia pela publicidade, não tinha e não tem interesse em movimentos que se revoltam e lutam por direitos. Então a Igreja tinha

\footnotetext{
${ }^{4}$ Maurício Amorim faleceu no dia 28 de janeiro de 2016 e atuou na Pastoral Operária até o fím de sua vida. Quando começou a organizar os trabalhadores para formação da pastoral trabalhava no Porto de Vitória. Chegou a atuar como sindicalista no Sindicato dos Arrumadores.

${ }^{5}$ Campo Grande é o principal bairro do município de Cariacica, vizinho a Vitória.

${ }_{7}^{6}$ Jean Fugeray faleceu em 2005.

${ }^{7}$ Militante da Pastoral Operária falecido em 20 de janeiro de 2012, Waldemar era uma das lideranças entre os trabalhadoras da construção civil que comandavam o grupo de oposição ao sindicato, que estava nas mãos dos patrões.

${ }^{8}$ Principais jornais de massa da época. Somente O Diário já não existe mais.
} 
que promover a formação e informação de suas lideranças para atuarem no mundo fora da Igreja. (LODI, 2016, informação verbal).

Claudio Humberto Vereza Lodi relata que a Pastoral Operária, quando procurou o Cedives, já tinha em mente como seria o informativo.

Eles falaram: "vai ter notícias do movimento sindical, de oposição, o que os documentos da Igreja orientavam sobre o papel do cristão no mundo do trabalho e na sociedade.. Isso foi evoluindo na questão da política do ponto de vista mais genérico, movimento popular de bairro, movimento negro, movimento de trabalhadores rurais. Teria sempre textos reflexivos para gerar reunião de grupos da Pastoral Operária, servir de subsídios na reunião e trazer notícias nacionais de boletins de Igreja ou não, de sindicatos e outras arquidioceses, como o Movimento Custo de Vida, movimento popular forte em São Paulo, primeiras greves que surgiram no ABC. A logomarca com a chave de fenda eu tirei de uma publicidade de loja de ferramentas. Pensei: "isso aqui vai dar certinho. Coloca a palavra ferramenta no meio da logo e fica muito bacana". Eu e Tereza fazíamos a redação. Traduzíamos para a linguagem popular. Frases curtas e resumido. Sempre com ilustração, para permitir o debate a partir do desenho. Era mensal. Com o tempo a própria equipe da Pastoral Operária foi elaborando, pois por volta de1979 a equipe do Cedives se resumiu a mim. Tereza saiu, os bispos preferiram não ter mais aqueles contratados, Dom Luiz Gonzaga Fernandes foi transferido, muitos agentes de pastoral também foram transferidos. Quando Padre Gabriel ${ }^{9}$ chegou, em 1980, ele assumiu mais o Ferramenta. (LODI, 2016, informação verbal).

Abaixo, capa da edição ${ }^{\circ} 0$ do Ferramenta, lançada em dezembro de 1977, com apoio da equipe do Cedives (Figura 1).

Figura 1 - Capa da primeira edição do Ferramenta, dez. 1977.

\footnotetext{
${ }^{9}$ Padre Gabriel Félix Roger Maire, francês, chegou ao Espírito Santo, mais precisamente ao município de Cariacica, em 1980. Engajou-se em diversas causas populares, como as dos operários, jovens, mulheres, na luta por moradia, entre outros. Em razão de sua atuação política, recebeu várias ameaças de morte, que se concretizaram em 23 de dezembro de 1989. Seu assassinato permanece impune até hoje.
} 


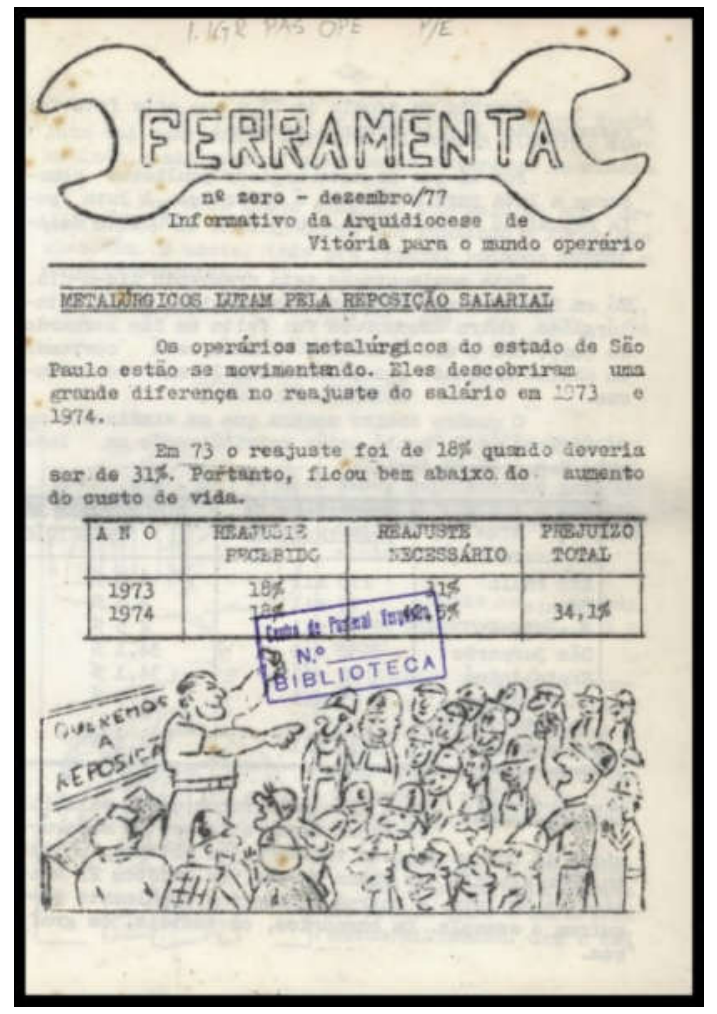

Fonte: www.cpvsp.org.br

Um aspecto destacado pelo aposentado e militante da Pastoral da Operária da

Arquidiocese de Vitória, José Lopes do Rosário, é que os próprios trabalhadores participavam do processo de produção do jornal.

Participávamos de reuniões semanais com Padre Gabriel, onde os trabalhadores relatavam os problemas vividos no ambiente de trabalho e debatiam. Eu, por exemplo, conversava com os colegas na hora do almoço e levava tudo para a reunião. Muitas vezes percorríamos eventos da Igreja no interior do Estado para conversar com os trabalhadores do campo e trazer suas demandas, além de distribuir o informativo. Diante das discussões trazidas, Gabriel preparava os textos. (ROSÁRIO, José Lopes do, 2016, informação verbal).

O jornalista e professor do Departamento de Comunicação Social da

Universidade Federal da Bahia (UFBA), Giovandro Marcus Ferreira, recorda que a preparação dos textos não era feita somente por Padre Gabriel, mas por uma equipe de comunicadores voluntários, entre eles, seminaristas e estudantes de comunicação.

Comecei a atuar no Ferramenta a convite do Gabriel. Eu era seminarista e estudante de jornalismo. E ele dizia que, além de padre, o sonho dele era ser jornalista. Aí criou-se uma grande afinidade entre nós. Lembro que tínhamos uma reunião de preparação de pauta. Aí a gente via o que estava em voga no campo eclesial e no campo sociopolítico. O Gabriel estava sempre com o radar mais ligado, sobretudo porque frequentava os grupos da Pastoral Operária, discutia 
também com os trabalhadores, e tinha sempre as proposições. Dividíamos as pautas. $\mathrm{Na}$ outra reunião cada um trazia o que havia escrito e avaliava. Depois era preciso datilografar, enviar para o desenhista e depois para a gráfica. (FERREIRA, 2016, informação verbal).

O próximo passo, a distribuição, destaca-se, segundo a pedagoga aposentada e tesoureira da Associação de Amigos de Gabriel Maire ${ }^{10}$, Carlinda Januário do Rosário, pelo fato de não se resumir a entregar o informativo de mão em mão ou a colocá-lo em locais considerados estratégicos para as pessoas interessadas em lê-lo poderem ter acesso ao exemplar.

Foram formados grupos de leitores nas comunidades. As pessoas recebiam o Ferramenta em casa, entregue por um representante da Pastoral Operária. Para receber o informativo pagava-se um valor simbólico para manutenção do jornal. Depois marcava-se uma data para que as pessoas se reunissem e debatessem os temas abordados na edição daquele mês. Esses debates criaram em muita gente nas comunidades uma reformulação do pensamento, criou consciência crítica e contribuiu com o crescimento dos movimentos sociais, pois levou muitas pessoas a participar deles. (ROSÁRIO, Carlinda Januário do, 2016, informação verbal).

As reflexões proporcionadas nas comunidades por meio do Ferramenta eram baseadas no método ver, julgar e agir, ou seja, o estudo de uma determinada realidade, a reflexão sobre ela e quais as ações concretas que aquele grupo poderia colocar em prática para que essa realidade possa mudar, segundo Giovandro Marcus Ferreira (2016, informação verbal).

Existia a preocupação de no final das matérias levantar algumas questões para o debate. Ou quando não levantávamos, orientávamos para quem estivesse dirigindo o grupo para que puxasse as reflexões. $\mathrm{O}$ ver era a leitura da matéria. O julgar, a reflexão sobre o que foi lido, como a importância do engajamento no bairro e no sindicato, por exemplo. O agir, a ação concreta, criar associação de moradores, fazer aniversário do buraco e chamar imprensa. (FERREIRA, 2016, informação verbal).

Ferreira (2016, informação verbal) destaca que existia a "preocupação de catalisar a imprensa de massa, ou imprensa burguesa", o que ele considera uma dicotomia, pois “a Igreja tinha uma reflexão muito crítica em relação a essa mídia, por isso que talvez tenha demorado a ter uma participação maior nos meios de comunicação de massa". Ela achava, de acordo com o professor (2016), que "as comunidades seriam a semente de uma nova sociedade, que as publicações alternativas e populares seriam

\footnotetext{
${ }^{10}$ Associação que tem como objetivo desenvolver trabalhos sociais em bairros da região de Porto de Santana, em Cariacica, uma das localidades onde Padre Gabriel atuou.
} 
semente de uma nova maneira de comunicar". Para ele, "o Ferramenta concretizou a preocupação da Igreja em fazer a reflexão do mundo operário, se aproximando desse mundo, emergindo desse mundo", pensando "uma comunicação a partir do lugar do pobre, no caso aí, do trabalhador" (FERREIRA, 2016, informação verbal).

A igreja buscava, sobretudo, a partir das conferências latino-americanas, afirma Ferreira (2016, informação verbal), "se colocar num outro lugar de fala em nossa sociedade", contribuindo "para repensar o lugar da Igreja a partir do lugar desse operário".

\begin{abstract}
Era uma instituição que buscava se articular de maneira mais horizontal internamente, criando novas estruturas na Arquidiocese de Vitória e se articular com os setores menos favorecidos. O Ferramenta era ligado à Igreja, que faz parte desse contexto maior de redirecionamento institucional, buscando, o que se falava muito na época, a opção preferencial pelos pobres. Seria muita pretensão dizer que o Ferramenta conseguiu mobilizar a classe trabalhadora. Ele mobilizava parte da classe trabalhadora, sobretudo a partir de lideranças ligadas a ela, como na construção civil, metalúrgicos, ferroviários e portuários. (FERREIRA, 2016, informação verbal).
\end{abstract}

Além do valor simbólico da assinatura do jornal, Padre Gabriel também passou a utilizar outro recurso para auxiliar na manutenção do Ferramenta. Segundo Mosquem et al. (2016, p. 106), o sacerdote recebia doações oriundas de seu país de origem, a França, as quais destinava para fundos de solidariedade a grevistas, construção de centros pastorais e para o boletim Ferramenta.

\title{
O Ferramenta e a greve da construção civil
}

O Ferramenta deu sua contribuição para a deflagração da greve dos trabalhadores da construção civil, a primeira paralisação ocorrida no Espírito Santo durante a Ditadura Militar (VOGAS, 2005). A greve aconteceu em setembro de 1979 e suas principais lideranças eram atuantes na Pastoral Operária. O último movimento paredista da categoria tinha sido em 1934 (DOIMO, 1986). De acordo com José Lopes do Rosário, com o passar do tempo a Pastoral Operária passou a compreender que era necessário tomar os sindicatos das mãos dos patrões, formando, então, chapas de oposição.

Vim de Barra de São Francisco ${ }^{11}$ em 1974 para trabalhar na Companhia Siderúrgica de Tubarão, na área da construção civil. Porém, meu contrato venceu e fui mandado embora. Isso era prática

\footnotetext{
${ }^{11}$ Município do interior do Espírito Santo
} 
comum na CST. Posteriormente fui trabalhar na empresa Metro, em Jardim da Penha, também na construção civil. Ingressei na Pastoral Operária a convite dos amigos Maurício Amorim e Waldemar Almeida Lyrio. Não tinha consciência de que os direitos dos trabalhadores não eram respeitados. Depois que entrei na Pastoral passei a participar de discussões sobre isso e comecei a entender que as empresas estavam erradas na maneira como tratavam os trabalhadores. Eu ia para a empresa com uma bolsa cheia de exemplares do Ferramenta para distribuir e promover discussões entre os trabalhadores. Chegou um momento que para tentar impedir a distribuição e outras atividades da Pastoral me colocaram para fazer atividades mais isoladas, para me separar dos colegas de trabalho. Com o passar do tempo entendemos que deveríamos tomar os sindicatos dos patrões. Passamos a participar das assembleias dos sindicatos, denunciar a violação dos nossos direitos, mas o presidente não ficava do nosso lado. Na greve da construção civil de 1979, entre as principais queixas dos operários estavam o arrocho salarial, o não pagamento de horas extras e a desigualdade salarial entre os trabalhadores (ROSÁRIO, José Lopes do, 2016, informação verbal).

A questão da desigualdade salarial entre os trabalhadores está registrada na edição n ${ }^{o} 10$ do Ferramenta, de novembro de 1978.

Dos 120 mil trabalhadores da indústria no Espírito Santo, mais de 60 mil operários não recebem salários conforme a sua classificação profissional. Os setores mais atingidos por essa injustiça são os da Construção Civil, Panificação e Carnes e Derivados. A própria Federação dos Trabalhadores na Indústria reconhece e diz que esta irregularidade vem do hábito de se registrar o novo empregado como servente ou ajudante, sem levar em conta sua classificação profissional. Mesmo trabalhando como carpinteiro, pedreiro ou outra profissão, na carteira continua como ajudante ou servente. (CONSTRUÇÃO CIVIL, nov. 1978, p. 6).

Greves de diversas categorias profissionais de vários locais do país foram registradas no Ferramenta, como a dos metalúrgicos de São Paulo, Guarulhos e Osasco, na edição de dezembro de 1978 do informativo (Figura 2).

Figura 2 - Capa da edição nº 11 do Ferramenta, dez. 1978. 


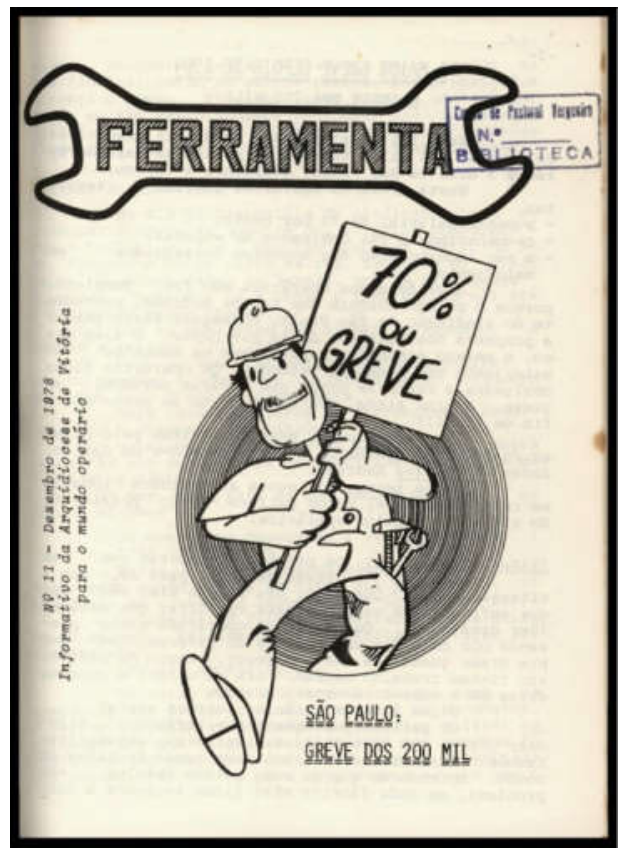

Fonte: www.cpvsp.org.br

As lutas dos operários da construção civil também foram registradas em diversas edições do Ferramenta. Em destaque, notícia divulgada na edição de setembro de 1979:

Construção Civil de Vitória

Na última Assembléia do dia 11 de agosto, foi formada uma Comissão de operários para discutir o piso salarial com os patrões. Esta Comissão entrou em negociação com os patrões. Os patrões não aceitaram a proposta de piso salarial feita pelo Sindicato e disseram que dariam $20 \%$ de aumento. Os operários não aceitaram a proposta oferecida pelos patrões. Diante desta situação, em que os patrões não aceitaram o piso salarial reivindicado pelos trabalhadores, ficou decidido que o Sindicato na Indústria de Construção Civil fará uma tabela progressiva que seria discutida no sábado, dia 25 de agosto. A tabela que vai ser feita pelo Sindicato é explicada pelo Delegado Regional do Trabalho: "Os trabalhadores fariam uma tabela onde aqueles que ganham menos tivessem porcentagem maior de aumento, diminuindo para aqueles que ganham mais". Acontece que o piso salarial é uma reivindicação de toda a classe dos trabalhadores. Esta luta está sendo levada em todo o Brasil. ASSIM FIZERAM os trabalhadores de Belo Horizonte, Brasília, Porto Alegre e de Goiás, que estão em greve exigindo um piso salarial para a categoria. Este piso salarial, que os trabalhadores estão exigindo há mais de 6 meses e que o presidente do sindicato vem sempre adiando, já perdeu para o aumento do custo de vida. Só este ano, o custo de vida já subiu, até agora, $16 \%$. Os $20 \%$ que os patrões ofereceram é uma oferta que ofende os trabalhadores. Pois o salário que os trabalhadores vêm recebendo não dá nem para acompanhar o aumento do custo de vida, com os preços subindo sempre. Por este motivo, não dá para aceitar a proposta dos patrões. A luta é pelo piso salarial, para os trabalhadores tentarem melhorar um pouco suas condições de vida. (CONSTRUÇÃO CIVIL DE VITÓRIA, set. 1979, 
p. 2).

Em outubro de 1979, o Ferramenta fez uma edição especial sobre a greve da Construção Civil em Vitória, detalhando todo o processo de negociação antes do movimento paredista, como se deu a deflagração da greve, quais foram as conquistas alcançadas, além de reforçar a necessidade dos operários continuarem mobilizados (Figura 3).

Figura 3 - Capa da edição no 21 do Ferramenta, out. 1979.

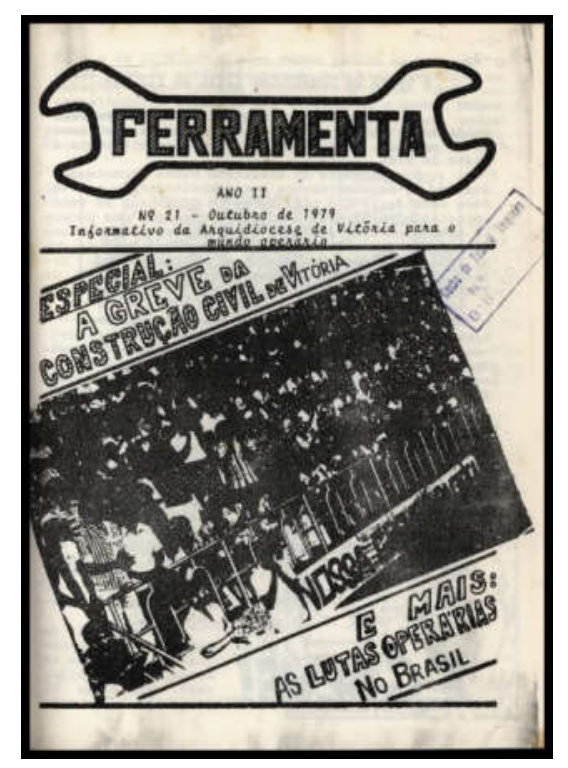

Fonte: www.cpvsp.org.br

Em São Paulo, a oposição metalúrgica crescia, encontrando terreno fértil entre os trabalhadores capixabas, incluindo os da Construção Civil (DOIMO, 1986). A edição de maio de 1978 do Ferramenta traz um texto para explicar aos trabalhadores o que é uma oposição sindical:

\section{Oposição sindical - O que é?}

Desde 1964 os sindicatos existentes deixaram de representar os interesses da Classe Operária. Dominados por diretorias "pelegas", controlados pelo Ministério do Trabalho, pelo Governo, os sindicatos se transformaram em órgãos de assistência (médico-dentária) e deixaram de lado as reivindicações mais importantes dos trabalhadores, como: aumento de salário, direito de greve, liberdade sindical. Por cansa dessa situação, os trabalhadores perderam, com razão, o interesse de participar do sindicato. É para lutar contra este sindicato de "pelegos", atrelado aos patrões, um sindicato que nada faz pelos trabalhadores, que surge a OPOSIÇÃO SINDICAL. Para conscientizar os operários dos seus direitos, para levar adiante a luta por melhores salários, pelo direito de greve, liberdade sindical, por 
melhores condições de trabalho. SOMENTE A CLASSE UNIDA E ORGANIZADA PODE MUDAR A SITUAÇÃO! (OPOSIÇÃO, maio 1978, p. 3).

Em agosto de 1979 a chapa de oposição dos trabalhadores da Construção Civil, a Chapa 2, já estava montada e o Ferramenta dedicou uma página e meia sobre o surgimento, apresentação dos componentes, seus cargos, propostas e defesa do porquê votar nela (Figura 4).

Figura 4 - Edição no 19 do Ferramenta, ago. 1979.

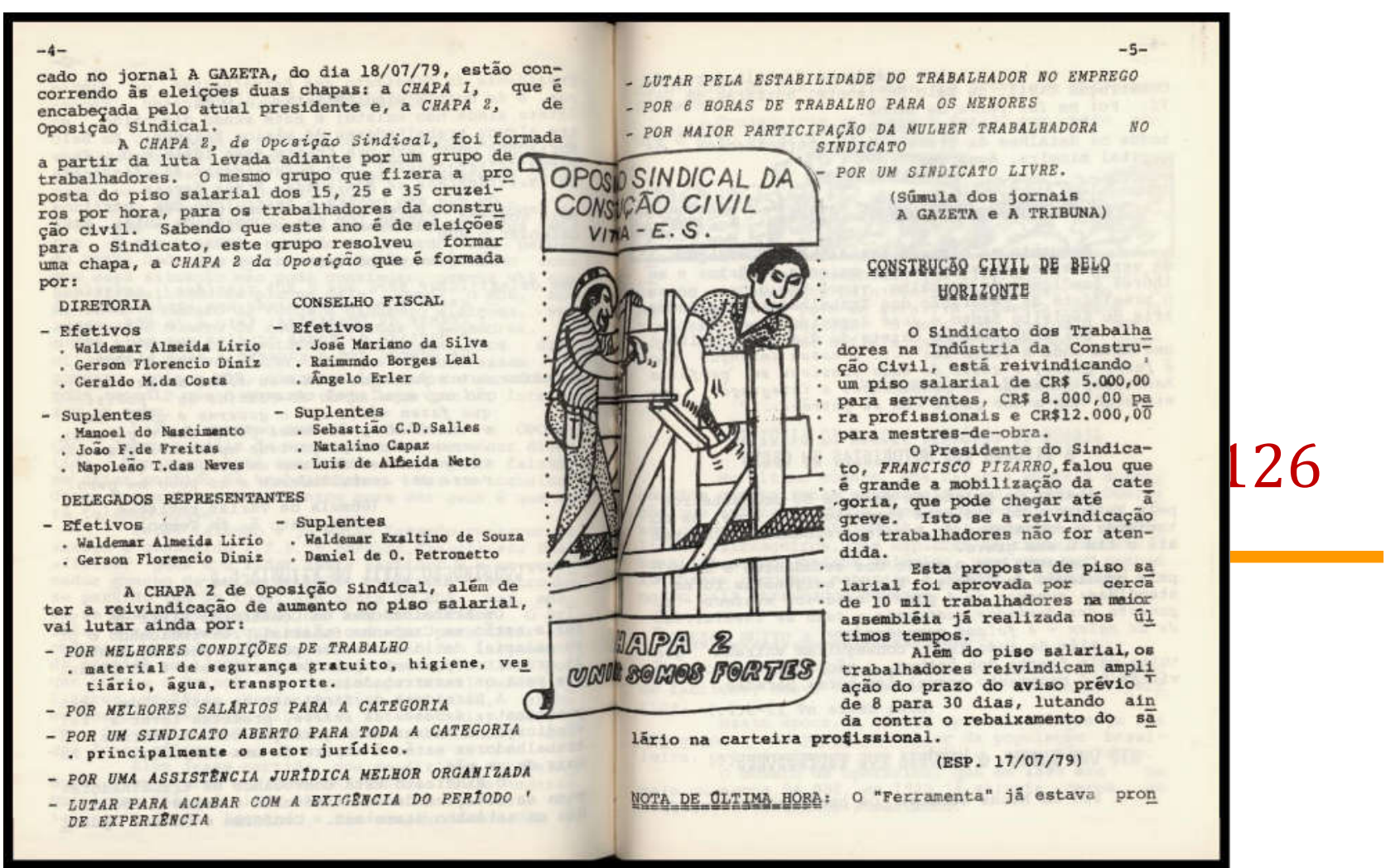

Fonte: www.cpvsp.org.br

Na edição de junho de 1980, o boletim Ferramenta denuncia as constantes anulações das eleições do Sindicato dos Trabalhadores da Construção Civil:

\section{Eleição no Sindicato da Construção Civil}

Os companheiros da Construção Civil continuaram lutando para mudar a Diretoria do Sindicato. Já houve 3 votações em que a Oposição Sindical sempre saiu vitoriosa. Mas os pelegos e a DRT as anularam. Nesta luta vamos descobrindo que a estrutura sindical realmente só serve para dificultar a nossa luta. É por isso que a Oposição Sindical não desiste. Esta legalização sindical vigora desde 1943, quando Getúlio Vargas atrelou o sindicato ao Ministério do Trabalho. Mesmo depois da CHAPA 2 ter ganhado, a DRT anulou as 
eleições e colocou interventor no sindicato, tentando desanimar os companheiros. Agora, no dia 29 de junho, vai ter nova votação. A Oposição Sindical registrou a CHAPA 2 para concorrer novamente. Para poder votar, os trabalhadores terão que estar em dia com o sindicato, pagando - no máximo até dia 19 - a sua mensalidade. (ELEIÇÃO, jun. 1980, p. 5)

Na mesma edição, vê-se uma das características do Ferramenta ressaltada por Giovandro Marcus Ferreira, que é a prática de deixar algumas perguntas a serem respondidas em grupos de reflexão sobre o conteúdo do informativo nos locais de trabalho, nas comunidades e grupos de Pastoral Operária. Diante da anulação das eleições do Sindicato dos Trabalhadores da Construção Civil, o informativo incita reflexões a partir de duas perguntas:

- Como estamos discutindo com os nossos companheiros e divulgando, no nosso serviço, a eleição do nosso sindicato?

- Como as outras categorias estão vendo esta eleição do sindicato da Construção Civil? (ELEIÇÃO, jun. 1980, p. 6)

E, finalmente, o reconhecimento da vitória da Chapa 2, noticiado na edição de agosto de 1980 .

Chapa 2 ganhou

No ano passado os trabalhadores da Construção Civil começaram as eleições do Sindicato. Todo mundo sabe que a Chapa 2 que é de Oposição Sindical, sempre teve maioria de votos. Mas os patrões e o DRT não permitiram a posse dos companheiros. Para esta última votação deveriam votar 528 trabalhadores. Mas as manobras dos pelegos, patrões e DRT cansaram os eleitores. Mesmo assim votaram 411. Dando uma vitória de 325 votos para a CHAPA 2, 70 para a CHAPA 1, 10 nulos e 6 brancos. 82,3\% dos votos válidos foram para a CHAPA 2. Isto mostra que os trabalhadores estão contra esta estrutura sindical pelega. Os companheiros querem o sindicato dirigido por verdadeiros trabalhadores! (CHAPA 2, ago. 1980, p. 1).

\section{Conclusões}

Um veículo de comunicação, por si só, não é capaz de mobilizar um determinado grupo. Existe uma série de fatores que, aliados a um informativo com uma linguagem e projeto gráfico que sejam atrativos ao público alvo, no caso dos impressos, influenciam nos resultados que esse veículo quer atingir. A fala dos entrevistados deixa claro que o Ferramenta foi criado para ser um instrumento de mobilização dos trabalhadores por parte da Pastoral Operária da Arquidiocese de Vitória. Também se percebe na fala deles que o informativo teve êxito em sua missão. 
Como afirma Giovandro Marcus Ferreira, essa mobilização se deu principalmente entre as categorias profissionais em meios às quais a Pastoral Operária tinha mais penetração, como ferroviários, metalúrgicos e operários da construção civil. Logo, o engajamento das lideranças da Pastoral em meio a essas categorias, aliado ao Ferramenta, potencializou a capacidade de mobilização.

Há, ainda, outros fatores importantes. O Ferramenta nasceu num contexto em que a Pastoral Operária tinha apoio institucional da Arquidiocese de Vitória, que forneceu espaço na Mitra para as reuniões, sacerdotes progressistas para acompanhar os trabalhos da Pastoral, cursos de formação e outras iniciativas que impulsionaram o trabalho dessa e de outras pastorais. Logo, havia um investimento da Igreja na formação de lideranças, que engajaram-se de fato na atividade de mobilização dos trabalhadores.

Um dos instrumentos escolhidos pela Pastoral Operária para ser instrumento de mobilização foi a comunicação popular. A escolha desse tipo de comunicação para auxiliar na tarefa foi correta. Analisando os conceitos de comunicação popular e pastoral social, destacados neste artigo, percebe-se que eles se assemelham bastante. Ambas, as pastorais sociais e a comunicação popular, têm como alguns de seus objetivos organizar os excluídos e promover mobilizações sociais. Portanto, a comunicação popular pode ser parte integrante do trabalho de uma pastoral, um instrumento importante para o êxito de suas atividades.

Logo, o sucesso do Ferramenta na mobilização dos trabalhadores, principalmente das categorias que sofriam influência maior da Pastoral Operária, está na junção de diversos fatores, como o apoio institucional da Arquidiocese de Vitória, o engajamento das lideranças da Pastoral e, também, o contexto de mobilizações populares ocorridas Brasil a fora, como a greve dos Metalúrgicos do $\mathrm{ABC}$, mencionada neste artigo. Muitas delas também foram impulsionadas pelas Comunidades Eclesiais de Base da Igreja Católica.

O Ferramenta se enquadra no conceito de comunicação popular não somente pelo seu objetivo de promover reflexão e mobilização, mas também por contar com seu público alvo, a classe trabalhadora, não somente como leitores, mas como partícipes do processo de produção, levando as demandas dos operários para as reuniões de pauta, onde eram discutidas coletivamente, selecionadas para integrar a edição do jornal, distribuído pelos próprios trabalhadores.

O método de distribuição é um fator importante para o êxito do jornal. Como 
destacou a entrevistada Carlinda Januário do Rosário, ele não era apenas lido individualmente por cada trabalhador que o recebia, e sim, refletido em grupo nos locais de trabalho e nas comunidades. Denota-se a preocupação de não somente levar a informação, mas também de fazer com que o leitor refletisse sobre ela, inclusive, debatesse com pessoas de seu cotidiano, com quem vivia problemas em comum e com quem poderia se unir para resolver esses problemas.

A maneira de captar as pautas também contribuiu para que o jornal auxiliasse a Pastoral em seu trabalho de mobilização, uma vez que a seleção de notícias partia da realidade do público alvo. Entre os pauteiros estavam os próprios trabalhadores, lideranças da Pastoral Operária que em seu ambiente de trabalho captavam as angústias do operariado, as situações de opressão, depois transformadas em notícias. Portanto, o leitor se via, se identificava naquele informativo.

Quanto à greve da construção civil de 1979, como afirma Ana Maria Doimo, a Pastoral Operária teve grande influência nesse movimento paredista. E como o Ferramenta era o principal veículo de comunicação da Pastoral, operando nos moldes já discorridos, certamente ele deu sua contribuição para isso. Essa greve foi destacada no artigo por ter sido a primeira no estado do Espírito Santo a ocorrer durante o período militar. O Ferramenta, contrapondo-se à grande mídia, trazia informações sobre as principais manifestações operárias ocorridas no Brasil, fazendo ecoar esses ideais em meio aos operários.

O informativo também incentivava os movimentos de oposição sindical, inclusive, explicando do que se tratava, conforme exposto neste artigo. Denunciava os sindicatos pelegos e apoiava chapas de oposição, como a da construção civil. A matéria sobre a chapa de oposição da construção civil era uma verdadeira propaganda eleitoral, que adentraria as fábricas e chegaria às mãos dos operários por meio dos agentes de Pastoral. Levando em consideração o fato de que todo esse conteúdo não era apenas lido individualmente por cada trabalhador que recebia o jornal, e, sim, refletido em grupo nos locais de trabalho e nas comunidades, o Ferramenta trouxe reflexões sobre a realidade dos trabalhadores, a necessidade da mobilização popular para mudar a realidade, inclusive com a tomada dos sindicatos das mãos dos patrões, que levaram seus leitores à ação.

Submetido em 30.11.2016

Aceito em 13.04.2017 


\section{REFERÊNCIAS BIBLIOGRÁFICAS}

BOURGUIGNON, Vitor. Impressões capixabas: 165 anos de jornalismo no Espírito Santo. In: MARTINUZZO, José Antônio (Org.). Departamento de Imprensa Oficial do Espírito Santo, 2005.

CHAPA 2 ganhou. Ferramenta, Vitória, p. 01, ago, 1980. Disponível em: $<$ http://www.cpvsp.org.br/upload/periodicos/pdf/PFERMES081980031.pdf>. Acesso em: 10 nov. 2016.

CONFERÊNCIA NACIONAL DOS BISPOS DO BRASIL. A missão da Pastoral Social. Brasília, Edições CNBB, 2008.

CONSTRUÇÃO Civil. Ferramenta, Vitória, p. 06, nov. 1978. Disponível em: $<$ http://www.cpvsp.org.br/upload/periodicos/pdf/PFERMES111978010.pdf >. Acesso em: 10 nov. 2016.

CONSTRUÇÃO Civil de Vitória. Ferramenta, Vitória, p. 02, set. 1979. Disponível em: $<$ http://www.cpvsp.org.br/upload/periodicos/pdf/PFERMES091979020.pdf >. Acesso em: 10 nov. 2016.

DOIMO, Ana Maria. Movimento social urbano, igreja e participação popular. Petrópolis: Vozes, 1984.

ELEIÇÃO no Sindicato da Construção Civil. Ferramenta, Vitória, p. 05, jun. 1980. Disponível

em:

$<$ http://www.cpvsp.org.br/upload/periodicos/pdf/PFERMES081979019.pdf>. Acesso em: 10 nov. 2016.

GIANNOTTI, Vito. História das lutas dos trabalhadores no Brasil. Rio de Janeiro: Mauad, 2007.

GURGel, Antônio de Pádua. Dom João Batista da Mota e Albuquerque. Vitória: Contexto, Jornalismo e Assessoria Ltda, 2005.

GUTIÉRREZ, Gustavo. Teologia da Libertação - Perspectivas. São Paulo: Loyola, 2000 .

MOSQUEM, D. et al. Ecos de Vitória. Editora Quatro Irmãos: Cariacica, 2016.

OPOSIÇÃO sindical - o que é. Ferramenta, Vitória, p. 03, maio 1978. Disponível em: $<$ http://www.cpvsp.org.br/upload/periodicos/pdf/PFERMES051978004.pdf >. Acesso em: 10 nov. 2016.

PERUZZO, Cicília M. Krohling. Aproximações entre a comunicação popular e comunitária e a imprensa alternativa no Brasil na era do ciberespaço. CONGRESSO BRASILEIRO DE CIÊNCIAS DA COMUNICAÇÃO, 31, Anais. Natal, 2008. Disponível em: <http://www.intercom.org.br/papers/nacionais/2008/resumos/R3-07161.pdf>. Acesso em: 25 jul. 2016.

PUNTEL, Joana T. A Igreja e a democratização da comunicação. São Paulo: 
Paulinas, 1994.

SALMÓN, Luis Ramiro Beltrán. La comunicacion para el desarrollo en latinoamerica: um recuento de medio siglo. Revista Iberoamericana de Comunicación. Málaga, $2005 . \quad$ Disponível em: $<$ http://www.infoamerica.org/teoria_textos/lrb_com_desarrollo.pdf $>$. Acesso em: 10 jul. 2016.

SIQUEIRA, Maria da Penha Smarzaro. Industrialização e empobrecimento urbano. O caso da Grande Vitória - 1950 a 1980. Vitória: Grafitusa, 2010.

\section{Entrevistas}

FERREIRA, Giovandro Marcus. Entrevista sobre o informativo Ferramenta. 2016. Entrevista concedida a Elaine Dal Gobbo via Skype, 20 nov. 2016.

LODI, Claudio Humberto Vereza. Entrevista sobre o informativo Ferramenta. 2016. Entrevista concedida a Elaine Dal Gobbo, Vila Velha, 20 maio 2016.

MACHADO, José Ferreira. Entrevista sobre o informativo Ferramenta. 2016. Entrevista concedida a Elaine Dal Gobbo, Cariacica, 05 nov. 2016.

ROSÁRIO, Carlinda Januário do. Entrevista sobre o informativo Ferramenta. 2016. Entrevista concedida a Elaine Dal Gobbo, Cariacica, 05 nov. 2016.

ROSÁRIO, José Lopes do. Entrevista sobre o informativo Ferramenta. 2016. Entrevista concedida a Elaine Dal Gobbo, Cariacica, 06 nov. 2016. 